\title{
Earnings Growth Potential Implicit in Price-Earnings Ratio
}

\author{
Jingying Zhou
}

Kunming Shengyi Join Harvest Equity Investment Fund Managament Co.,Ltd , Kunming , 650000, China

Keywords: P/E ratio, earnings growth rates, correlation, Beta

\begin{abstract}
P/E ratio has enjoyed high popularity as a simple tool to determine whether a stock is undervalued, but its determinants remain unclear and controversial. Earnings growth rate is regarded as a main factor. Looking backward, some theories perceives growth rates as randomly distributed across years thus offer no clue into the behavior pattern of $\mathrm{P} / \mathrm{E}$ ratios, while other studies claim contradictory conclusion. This article reexamines the problem from perspectives of theories and empirical studies based on data from 2007 to 2017 in China's domestic stock markets. Behavior patterns of $\mathrm{P} / \mathrm{E}$ ratios and earnings growth rates are interpreted and the risk factor $\beta$ is also incorporated in the analysis.
\end{abstract}

\section{Introduction}

Price-Earnings Ratio (denoted as "P/E ratio") indicates explicitly how much an investor is willing to pay for each unit of earnings the target company makes. Why do P/E ratios across corporations vary from each other? Differences in earnings growth rates may offer to be one explanation. Historically, a number of academic research has provided insights into how their relationship behaves. According to "Higgledy Piggledy Growth" theory [1], the distributions of earnings growth rates over time exhibit random pattern. However, Fuller, Huberts and Levinson have conducted an empirical study and arrived at the conclusion that low $\mathrm{P} / \mathrm{E}$ ratio tend to represent low subsequent earnings growth rate, vice versa. This finding reveals that investors may be able to distinguish across companies based on their future growth potential and then set their prices correspondingly [2].

Some manifest phenomenon in developed markets may not exist in emerging markets. Elapse of time is also a source of significant changes. The purpose of the article is to examine the correlation between P/E ratios and earnings growth rate in emerging markets, firstly, from the perspective of valuation theory. Then an empirical analysis is carried out by analyzing data from China's domestic stock market.

\section{Valuation Models}

Discounted Dividend Model (DDM) has bridged prices and earnings in a quantitative way. In his 1959' s article, Gordon evaluates a hypothesis that it is actually the dividends that an investor gets when purchasing a share and then he develops it into the prestigious Gordon Growth Model [3]. This model is in the setting of perfect financial market and based on two additional assumptions. The first assumption is that dividends are growing at a constant rate and the second is that discount rate should exceed the dividend growth rate [4]. One criticism of Gordon Growth Model argues that it is unreasonable to assume constant high growth rate of dividends into perpetuity. Thus we extend the model into two-stage by distinguishing growth stages into a rapid growing stage with a high growth rate $\mathrm{gH}$ lasting for $\mathrm{n}$ years and a stable growing stage with a lower level of growth rate gL approximately equivalent to macroeconomic growth rate. Besides, we assume dividend payout ratio $\mathrm{b}$ is constant and express dividend as a product of earnings and b. Under this circumstance, the stock price constitutes two parts: values from the first rapid growth stage V1 and from the second stable growth stage V2. 
$P_{0}=V_{1}+V_{2}=\sum_{i=1}^{n} \frac{E_{0} \times b \times\left(1+g_{H}\right)^{i}}{(1+R)^{i}}+\frac{E_{0} \times b \times(1+g)^{n} \times\left(1+g_{L}\right)}{\left(R-g_{L}\right)}(1+R)^{n}$

We can get trailing $\mathrm{P} / \mathrm{E}$ ratio by dividing both sides by $\mathrm{E}_{0}$ :

$\frac{P_{0}}{E_{0}}=\sum_{i=1}^{n} \frac{b \times\left(1+g_{H}\right)^{i}}{(1+R)^{i}}+\frac{b \times\left(1+g_{H}\right)^{n} \times\left(1+g_{L}\right)}{\left(R-g_{L}\right) /(1+R)^{n}}$

Intuitively, holding other variables constant, it can be observed from Eq.2 that P/E ratio positively correlates with both $g_{H}$ and $g_{L}$. Therefore, for stocks with same level of total risk, higher potential for performance growth is compensated with higher relative price, which is represented as $\mathrm{P} / \mathrm{E}$ ratio.

\section{Data and Methodology}

When it comes to real world, inputs such as $b, R$ and $g$ tend to fluctuate over years, and the equation itself is challenged by numerous transitory and stochastic factors. All of these uncertainties may lead to complication and distortion. The empirical study's time span is ten consecutive years from 2007 to 2016. To calculate a stock's trailing P/E ratio in 2007, we need the price on March $31^{\text {st }}$, 2008 (or $29^{\text {th }}$ and $30^{\text {th }}$ if March $31^{\text {st }}$ happens to be a non-business day) as the nominator, and the previous year 2007's basic EPS as the denominator. The primary reason for selecting this date is that most companies issue their annual reports or performance preannouncements prior to March $31^{\text {st }}$ and no first quarter preannouncements are available at that time, eliminating influences from new operation information. Earnings data and stock prices are collected from Wind.

The population is all of the domestic stocks in Shanghai Stock Exchange and contains more than one thousand stock, with no particular industry, style or capitalization biases. We exclude stocks with two characteristics: 1. Prices are not available on any March 31st over the ten years, either due to suspension or having not listed yet. 2. Earnings are negative during any of these years since negative $\mathrm{P} / \mathrm{E}$ ratio can lead to distortion and incomparability. After filtering, 210 stocks remain.

\section{The Behavior Patterns for P/E Ratios over Time}

We rank these 210 stocks by their P/E ratios in 2006 in descending order and divide into fifteen equal-sized groups denoted from 1 to 15 . To remove effects from outliers, we calculate medians rather than means. Table 1 provides a descriptive statistic summary and the italic numbers below median are ranks for that year.

Table 1 Median P/E ratios of 15 groups during last 10 years (2007 to 2016) 


\begin{tabular}{|c|c|c|c|c|c|c|c|c|c|c|c|c|c|c|c|}
\hline Group No. & 1 & 2 & 3 & 4 & 5 & 6 & 7 & 8 & 9 & 10 & 11 & 12 & 13 & 14 & 15 \\
\hline \multirow[t]{2}{*}{2007} & 201.3 & 117.7 & 75.3 & 62.7 & 51.7 & 45.0 & 39.1 & 37.2 & 32.8 & 30.3 & 27.7 & 25.2 & 21.7 & 19.4 & 13.5 \\
\hline & 1 & 2 & 3 & 4 & 5 & 6 & 7 & 8 & 9 & 10 & 11 & 12 & 13 & 14 & 15 \\
\hline \multirow[t]{2}{*}{2008} & 112.0 & 44.2 & 54.3 & 39.0 & 28.6 & 27.7 & 33.1 & 30.6 & 31.5 & 32.9 & 24.4 & 23.4 & 20.0 & 22.2 & 22.6 \\
\hline & 1 & 3 & 2 & 4 & 9 & 10 & 5 & 8 & 7 & 6 & 11 & 12 & 15 & 14 & 13 \\
\hline \multirow[t]{2}{*}{2009} & 88.9 & 69.9 & 73.6 & 53.4 & 37.7 & 40.2 & 34.4 & 36.5 & 42.3 & 46.4 & 30.9 & 27.1 & 25.4 & 23.8 & 23.1 \\
\hline & 1 & 3 & 2 & 4 & 8 & 7 & 10 & 9 & 6 & 5 & 11 & 12 & 13 & 14 & 15 \\
\hline \multirow[t]{2}{*}{2010} & 88.6 & 47.6 & 51.7 & 42.6 & 32.1 & 40.7 & 34.7 & 32.3 & 31.8 & 31.3 & 34.2 & 24.5 & 17.4 & 20.4 & 21.7 \\
\hline & 1 & 3 & 2 & 4 & 9 & 5 & 6 & 8 & 10 & 11 & 7 & 12 & 15 & 14 & 13 \\
\hline \multirow[t]{2}{*}{2011} & 46.0 & 25.3 & 35.7 & 30.6 & 21.9 & 22.7 & 21.1 & 24.6 & 17.2 & 24.1 & 21.5 & 13.3 & 12.2 & 16.2 & 13.3 \\
\hline & 1 & 4 & 2 & 3 & 8 & 7 & 10 & 5 & 11 & 6 & 9 & 13 & 15 & 12 & 14 \\
\hline \multirow[t]{2}{*}{2012} & 45.4 & 34.7 & 40.8 & 37.4 & 22.3 & 23.5 & 22.7 & 22.4 & 26.9 & 25.1 & 18.1 & 15.3 & 13.5 & 16.1 & 17.6 \\
\hline & 1 & 4 & 2 & 3 & 10 & 7 & 8 & 9 & 5 & 6 & 11 & 14 & 15 & 13 & 12 \\
\hline \multirow[t]{2}{*}{2013} & 59.2 & 43.4 & 35.0 & 20.8 & 23.6 & 23.2 & 22.8 & 21.5 & 22.2 & 30.4 & 16.1 & 14.5 & 13.4 & 13.0 & 12.2 \\
\hline & 1 & 2 & 3 & 10 & 5 & 6 & 7 & 9 & 8 & 4 & 11 & 12 & 13 & 14 & 15 \\
\hline \multirow[t]{2}{*}{2014} & 101.6 & 69.8 & 73.4 & 28.1 & 39.6 & 38.9 & 41.9 & 42.8 & 31.8 & 35.8 & 40.3 & 29.2 & 23.8 & 22.9 & 18.7 \\
\hline & 1 & 3 & 2 & 12 & 7 & 8 & 5 & 4 & 10 & 9 & 6 & 11 & 13 & 14 & 15 \\
\hline \multirow[t]{2}{*}{2015} & 54.2 & 70.2 & 93.3 & 36.6 & 27.1 & 34.4 & 37.5 & 30.8 & 43.8 & 32.4 & 31.5 & 21.5 & 24.2 & 18.0 & 16.7 \\
\hline & 3 & 2 & $I$ & 6 & 11 & 7 & 5 & 10 & 4 & 8 & 9 & 13 & 12 & 14 & 15 \\
\hline \multirow[t]{2}{*}{2016} & 109.3 & 77.4 & 79.4 & 34.6 & 31.0 & 40.2 & 35.8 & 25.5 & 32.2 & 34.9 & 35.9 & 23.3 & 28.3 & 24.5 & 16.5 \\
\hline & 1 & 3 & 2 & 8 & 10 & 4 & 6 & 12 & 9 & 7 & 5 & 14 & 11 & 13 & 15 \\
\hline
\end{tabular}

A certain degree of persistence can be found among the first four groups and the last four. Though in differential orders, group 1 to 4 also tend to occupy the first four places with exceptions of group 4 in 2013, 2014 and 2016. Similar conclusion applies to 37 cases out of 40 for group 12 to 15. It is also impressive that group 1 have maintained its top place in nine out of the ten years. No clear evidence for constancy can be found in those seven groups in-between.

\section{The Behavior Patterns of Earnings Growth Rates over Time}

To exclude influences from dividends, stock splits and reverse splits, we utilize total earnings rather than EPS to derive earnings growth rates. Non-recurring items are deemed as transitory and more vulnerable to forgery, exaggeration and manipulation. Therefore, out of prudence and diligence, net incomes unadjusted and adjusted for non-recurring items are both collected, corresponding to two kinds of growth rates. Table 2 shows a comparison between these two series of data.

Table 2 Summary Statistics

\begin{tabular}{c|cccccc} 
& \multicolumn{2}{|c}{ Median } & \multicolumn{2}{c}{ Mean } & \multicolumn{2}{c}{ STDEV } \\
\hline Year & Unadjusted & Adjusted & Unadjusted & Adjusted & Unadjusted & Adjuster \\
2008 & $4.72 \%$ & $11.88 \%$ & $38.61 \%$ & $64.07 \%$ & 2.06 & 3.22 \\
2009 & $21.00 \%$ & $14.08 \%$ & $165.23 \%$ & $125.57 \%$ & 13.01 & 10.01 \\
2010 & $24.46 \%$ & $34.78 \%$ & $55.22 \%$ & $116.10 \%$ & 1.28 & 4.77 \\
2011 & $15.10 \%$ & $14.12 \%$ & $47.49 \%$ & $27.30 \%$ & 3.05 & 1.29 \\
2012 & $2.67 \%$ & $0.02 \%$ & $48.40 \%$ & $13.18 \%$ & 3.95 & 2.81 \\
2013 & $10.18 \%$ & $14.45 \%$ & $29.54 \%$ & $-11.21 \%$ & 1.19 & 6.42 \\
2014 & $9.77 \%$ & $7.95 \%$ & $41.18 \%$ & $16.28 \%$ & 1.55 & 1.28 \\
2015 & $2.85 \%$ & $3.45 \%$ & $502.39 \%$ & $682.57 \%$ & 66.02 & 87.94 \\
2016 & $10.47 \%$ & $10.61 \%$ & $39.62 \%$ & $52.33 \%$ & 1.28 & 2.78 \\
Total & $10.84 \%$ & $12.40 \%$ & $107.52 \%$ & $120.69 \%$ & 22.52 & 29.68
\end{tabular}

As indicated above, means deviate from medians considerably due to extraordinary outliers. This extreme long tails for the pair of mean distributions are mainly caused by restructuring and backdoor listing. Throughout this whole period, in contrast to earnings unadjusted for non-recurring items, adjusted earnings growth rates show greater means, medians and volatility, which indicates more conservative distribution. For simplicity, we utilize only unadjusted earnings to conduct following analysis and report the correlation matrix in Table 3. 
Table 3 Correlation Matrix

\begin{tabular}{c|cccccccc} 
& \multicolumn{8}{|c}{ Number of Years Following Base Years } \\
\hline Base year & 1 & 2 & 3 & 4 & 5 & 6 & 7 & 8 \\
2008 & -0.0679 & -0.0746 & -0.0280 & -0.0169 & 0.0050 & -0.0071 & -0.0411 & 0.0872 \\
2009 & -0.0537 & -0.0209 & 0.0415 & -0.0041 & -0.0469 & -0.0075 & 0.0004 & \\
2010 & -0.0502 & -0.0296 & 0.0550 & -0.0566 & 0.1600 & 0.0841 & & \\
2011 & -0.0291 & -0.0259 & -0.0556 & -0.0177 & -0.0568 & & & \\
2012 & -0.0364 & -0.0412 & -0.0143 & -0.0540 & & & & \\
2013 & -0.0608 & -0.0073 & -0.0615 & & & & & \\
2014 & -0.0314 & -0.0527 & & & & & & \\
2015 & -0.0478 & & & & & & &
\end{tabular}

In contrary to $\mathrm{P} / \mathrm{E}$ ratios which show manifest persistence, earnings growth rates possess subtle correlations very close to zero across years which implies that they do not persist into subsequent years. This evidence is consistent with the "Higgledy Piggledy Growth" theory mentioned before.

\section{The Behavior Patterns of Correlation between P/E ratios and Earnings Growth Rate}

To examine the relationship of earnings growth rates against $\mathrm{P} / \mathrm{E}$ ratios, we define earnings growth rates for three consecutive years $t-1, t, t+1$ (denoted as $g_{t-1}, g_{t}$ and $g_{t+1}$ ) as independent variables , and $\mathrm{P} / \mathrm{E}$ ratio for year $\mathrm{t}$ (denoted as $\mathrm{P} / \mathrm{E}_{\mathrm{t}}$ ) as the dependent variable. The regression model is constructed as:

$\frac{P}{E_{t}}=\alpha_{0}+\alpha_{1} \times g_{t-1}+\alpha_{2} \times g_{t}+\alpha_{3} \times g_{t+1}+\varepsilon$

Table 4 Regression Results against Growth Rates from Three Consecutive Years

\begin{tabular}{c|cccccc} 
& $\alpha_{0}$ & $\alpha_{1}$ & $\alpha_{2}$ & $\alpha_{3}$ & $\mathrm{R}^{2}$ & Adjusted $\mathrm{R}^{2}$ \\
\hline 2009 & $66.32 * * *$ & -3.70 & 0.02 & 0.69 & $1.10 \%$ & $-0.34 \%$ \\
2010 & $65.99 * * *$ & -0.20 & -3.40 & $22.97 * *$ & $3.35 \%$ & $1.95 \%$ \\
2011 & $36.59 * * *$ & -1.69 & $1.13 * *$ & $-9.01 * * *$ & $17.38 \%$ & $16.18 \%$ \\
2012 & $48.89 * * *$ & -3.83 & -7.26 & 0.79 & $1.52 \%$ & $0.08 \%$ \\
2013 & $51.25 * * *$ & -8.93 & -0.17 & -12.28 & $1.85 \%$ & $0.42 \%$ \\
2014 & $73.25 * * *$ & -0.77 & $-12.51 * *$ & $-2.01 * * *$ & $77.46 \%$ & $77.13 \%$ \\
2015 & $83.89 * * *$ & $-15.50 * *$ & 0.08 & $-25.42 * * *$ & $23.63 \%$ & $22.51 \%$
\end{tabular}

Note that $\alpha_{0}$ is the intercept and $\alpha_{1}, \alpha_{2}$, and $\alpha_{3}$ are coefficients for $g_{t-1}, g_{t}$ and $g_{t+1}$ respectively. Additionally, labels as $* * *, * *$ and * represent a figure is significant at level of significance of $1 \%$, $5 \%$ and $10 \%$ respectively, and these labels also apples to Table 5 . It can be observed that $\mathrm{P} / \mathrm{E}_{\mathrm{t}}$ tends to be highly negatively correlated with subsequent year' $s g_{t+1}$, which is contradictory to the conclusion reached by Fuller, Huberts and Levinson mentioned before. However, $\mathrm{g}_{\mathrm{t}-1}$ and $\mathrm{g}_{\mathrm{t}}$ provide weak prediction for $\mathrm{P} / \mathrm{E}_{\mathrm{t}}$. Notably, adjusted R-square across years are insignificant with only exception 2014. In general, this model could not fit the data series appropriately.

Then we introduce risk factor Beta $(\beta)$ from CAPM model to our analysis and regress it along with $g_{t}$ against $\mathrm{P} / \mathrm{E}_{\mathrm{t}}$. We derive $\beta$ from daily returns of both individual sample stocks and broad market index "Shanghai Composite Index". The regression result is shown in Table 4. Note that $\gamma_{0}$ is the intercept, and $\gamma_{1}, \gamma_{2}$ are coefficients for $g_{t}$ and $\beta$. Eq. 4 gives the new regression model.

$\frac{P}{E_{t}}=\gamma_{0}+\gamma_{1} \times g_{t}+\gamma_{2} \times \beta+\varepsilon$ 
Table 5 Regression Results against Growth Rates and Beta

\begin{tabular}{c|ccccc} 
& $\gamma_{0}$ & $\gamma_{1}$ & $\gamma_{2}$ & $\mathrm{R}^{2}$ & Adjusted $\mathrm{R}^{2}$ \\
\hline 2008 & $82.43^{*}$ & $-3.61 \&$ & -22.78 & $1.61 \%$ & $0.66 \%$ \\
2009 & 19.15 & -0.07 & 45.06 & $0.62 \%$ & $-0.34 \%$ \\
2010 & 46.87 & -2.34 & 21.13 & $0.52 \%$ & $-0.44 \%$ \\
2011 & 4.18 & 4.18 & 4.18 & $1.35 \%$ & $0.39 \%$ \\
2012 & 0.42 & -6.96 & 38.47 & $1.92 \%$ & $0.97 \%$ \\
2013 & 69.32 & 0.15 & -15.06 & $0.04 \%$ & $-0.93 \%$ \\
2014 & -27.43 & $-23.23 * *$ & $123.58 * * *$ & $5.80 \%$ & $4.89 \%$ \\
2015 & 81.33 & 0.04 & -1.30 & $0.07 \%$ & $-0.90 \%$ \\
2016 & $-126.69 *$ & -5.66 & 176.43 & $5.71 \%$ & $4.80 \%$
\end{tabular}

Reconstruction and incorporation of $\beta$ even offer weaker explanatory power compared to the previous model. Not only are adjusted R-square much lower, intercepts and coefficients are less significant. Nevertheless, an interesting fact is that in 2014 adjusted R-square in the first model reaches the highest level of $77.13 \%$, simultaneously, coefficients $\gamma_{1}$ and $\gamma_{2}$ in second model are also both significant. This may be coincident or due to some reasons, which is beyond the scope for this article.

\section{Conclusion}

This article explores the correlation between $\mathrm{P} / \mathrm{E}$ ratios and earnings growth rates through decomposition of valuation models and empirical studies based on past ten years' data. Discounted Dividend Model indicates a positive relationship. Although empirical studies based on data from China's domestic stock market show that P/E ratios possess some degree of persistence across different years, while on the other hand, growth rates tend to distribute stochastically. Regression models provide evidence that $\mathrm{P} / \mathrm{E}$ ratios may be inversely related with subsequent growth rates, which conflicts with results from previous empirical studies rooted in U.S markets. Additionally, it has been shown that introduction of risk factor $\beta$ does no help to a better fit. Indeed, disciplines in emerging markets are more easily distorted by transitory factors and various risks.

\section{References}

[1]Fuller,R.J., Huberts,L.C. and Levinson,M. It's Not Higgledy-Piggledy Growth![J]. Journal Portfolio Management, Winter,1992:38-45.

[2]Fuller,R.J., Hubert,L.C. and Levinson,M. Returns to E/P Strategies, Higgledy-Piggledy Growth, Analysts' Forecast Errors, and Omitted Risk Factors[J].Journal of Portfolio Management, 1993,19(2):13-24

[3]Grodon,M. Dividends, Earnings, and Stock Prices[J].The Review of Economics and Statistics,1959,41(2): 99-105

[4] Beaver,W. and Morse,D. What Determines Price-Earnings Ratios? [J]. Financial Analysts Journal, 1959,34(4): 65-76 